\title{
Histomorphological Effects of Cottonseed Oil on Testes in Adult Male Wistar Rats
}

\author{
Lilian Ebele Chris-Ozoko, Onome Okpe, Wilson Josiah lju, John Chukwuma Oyem
}

\begin{abstract}
Cottonseed oil is an extract from the seeds of cotton plant, that is rich in protein, carbohydrate and fiber. The objective of the research was to study the effect of cottonseed oil on the histology of the testis.

Materials and methods. Twelve adult male Wistar rats weighing $200-250 \mathrm{~g}$, were randomly sorted into four groups (I - IV), each containing three animals. Cottonseed oil was administered orally to the experimental animals by means of an orogastric tube. The rats in Group I (the control group) received standard rat pellet and oral normal saline ad libitum only. The animals in Groups II, III, and IV received $0.2 \mathrm{ml}, 0.6 \mathrm{ml}$ and $1.0 \mathrm{ml}$ of cotton seed oil per body weight respectively. On the $21 \mathrm{st}$ day, the animals were sacrificed by cervical dislocation. The testes were excised and, then, fixed with appropriate fixatives for routine tissue processing.

Results. The results revealed an increase in the luminal diameter of seminiferous tubules, a decrease in the Leydig cell population, the disorientation of spermatogenic series and their detachment from the germinal epithelium.

Conclusions. The present study demonstrated that oral administration of cottonseed oil to male rats displayed a deleterious effect on their testis by disrupting spermatogenesis and the histological architecture of the testis.
\end{abstract}

Keywords

gossypol; cottonseed oil; contraception; testes; spermatogenesis

Department of Human Anatomy and Cell Biology, Delta State University, Delta State, Abraka, Nigeria

*Corresponding author: Johnoyem2018@Gmail.com

\section{Problem statement and analysis of the latest research}

Cottonseed oil is an extract from the seeds of cotton plant. This extract is a good source of protein and energy being abundant in Central African countries. It has been applied in the production of salad oil, mayonnaise, salad dressing and similar products due to its flavor and stability [1].

Cotton is an arborous and fiber plant, that belongs to the family Malvaceae. Its genus species are Gossypium Herbaceum (Levant Cotton Root Bark) and Gossypium Hirsutum (Cotton Root Bark). Cotton is one of the earliest plants cultivated by man for over 4, 000 years [2]. It is produced perennially worldwide in tropical and subtropical regions. It is abundant in India, Southern Europe, and the USA [2].

Phytochemical screening of Cottonseed oils has revealed its high composition of tocopherols - a natural anti-oxidant which has a varying degree of vitamin E activity [3]. A study conducted by Shepu et al. (1980) also demonstrated the presence of a biologically active yellow compound called "Gossypol" $(0.6 \%)$ which has been linked to the male reproductive system, especially sperm count and has also been reported to be toxic to monogastric animals [4]. In 1958, Edwards JD showed that it had molecular weight of 518.54, and a structure of 2, 2'- binaphthalane -8, 8'- dicarboxyaldhyde - 1, 1'- 6, 6'7, 7'-hexahydroxy- 5, 5'- diisopropyl - 3, 3'-dimethy [5].
The research on the effect of gossypol on human subjects, monkeys and rats showed that the administration of gossypol resulted in the impairment of spermatogenesis and the reduction in sperm motility $[3,6,7,8]$. Similarly, another study conducted by Liang et al. in 1981 reported that gossypol caused a significant decrease in sperm count [9]. However, in 1957, Liu demonstrated a relationship between low fertility in males and crude cottonseed oil for cooking [10]. Consequently, gossypol has been tested as a male oral contraceptive in China [11].

In the mid-1990s, the Brazilian pharmaceutical company Hebron announced plans to market a low dose gossypol pill called Nofertil; however, the pill never came to market because its release was indefinitely postponed due to unacceptably high rate of permanent infertility [12].

In view of its use as an antifertility agent, in 1957, Liu reported that no single childbirth was recorded for as long as 10 years during the 1930's and 1940's in Wang village in Jiangsu province in China, while before this period, males were reported to be fertile [10].

Messiha (1991) stated that gossypol exerted its contraceptive action by inhibiting an enzyme called lactate dehydrogenese $\mathrm{X}$ playing a crucial role in energy metabolism in sperm and spermatogenic cells [13]. According to Velasquez et al., in 1999, gossypol exerted a degree of inhibition on lactate dehydrogenese $\mathrm{X}$, found only in sperm and male gonadal cells 
[13].

A study carried out by Paim et al. in 2015 showed that control animals had higher testosterone concentrations, lower total sperm defects, higher mass movement and higher scores for seminiferous epithelium than animals that received $20 \%$ high oil cottonseed meal at the end of the trial [14]. Groups that received $20 \%$ of dry matter intake of whole cottonseed and high oil cottonseed meal showed higher levels of segmental aplasia lesion in sperm than other diets, which showed that high levels of gossypol led to higher occurrence of this lesion. They further concluded that cottonseed coproducts had a negative impact on the reproductive system of pubertal lambs regardless of gossypol concentration [14].

Kenfack et al. (2015) conducted a study which was aimed at investigating the effect of cottonseed cake on the fertility of male rabbits [15]. Findings from this study showed that cottonseed cake had no effect on the weight, the volume and the histological structure of genital organs [15]. The results from this study also indicated that hundred percent of rabbits realized mounting and ejaculated whichever the cottonseed cake level was; nevertheless, the volume of the ejaculate was significantly ( $\mathrm{p}>0.05)$ lower in rabbit fed $6 \%$ cottonseed cake (0.86 vs $1.66,12 \%)$ [15].

Several studies have demonstrated the effect of cottonseed oil on the male reproductive system using higher concentrations, others have concentrated on ejaculation time, sperm motility and its spermicidal activity [1, 6, 9]. Literature has described it as a contraceptive agent, but only few studies have been specifically devoted to the testicular cellular changes that result from the oral administration of cottonseed oil and its products $[15,16,17]$.

Hence, the objective of this research was to investigate the histomorphological effect of low dose of cottonseed oil on the testis of adult Wistar rats to discern what homologous effects cottonseed oil will have on humans.

\section{Materials and Methods}

\subsection{Collection of plant material}

Cottonseed oil was purchased from the cottonseed oil company in Funtua, Katsina State, Nigeria. The manufacturers details, batch number and expiration date of cottonseed oil were taken into consideration.

\subsection{Experimental animals}

The experiment was conducted with twelve adult male albino rats weighing between 200-250g obtained from animal house of Basic Medical Sciences, College of Health Sciences, Delta State University, Abraka. The animals were allowed to acclimate to the laboratory condition (temperature of $24-28^{\circ} \mathrm{C}$ and 12-hour light-dark cycle) for two days before commencement of the experiment with free access to rat chow (Top feeds Nigeria) and water ad libitum throughout the study. All the animals were treated according to guiding principles in the care and use of animals as stated by Animal Research Ethics.
The approval was received from a Local Research Ethical Committee of the university [18].

\subsection{Experimental Design}

The experimental animals were randomly divided into four groups I, II, III and IV containing three rats in each group $(n=4)$. The rats in Group I (the control group) received standard rat chow and oral normal saline ad libitum only. Groups II, III, and IV received $0.2 \mathrm{ml}, 0.6 \mathrm{ml}$ and $\mathrm{I} .0 \mathrm{ml}$ of cottonseed oil together with rat chow and normal saline ad libitum, respectively. On the $21^{\text {st }}$ day of treatment, the animals were euthanized by cervical dislocation. The testes were harvested and fixed with appropriate fixatives for routine tissue processing according to standard histological techniques.

\subsection{Photomicrography}

Haematoxylin and Eosin Stained tissue images were captured using digital microscopic eyepiece "SCOPETEK" DCM 500, 5.0 mega pixel connected to computer.

\section{Results}

Plates 1-4 demonstrate histological effects of cottonseed oil on the testes of experimental rats.

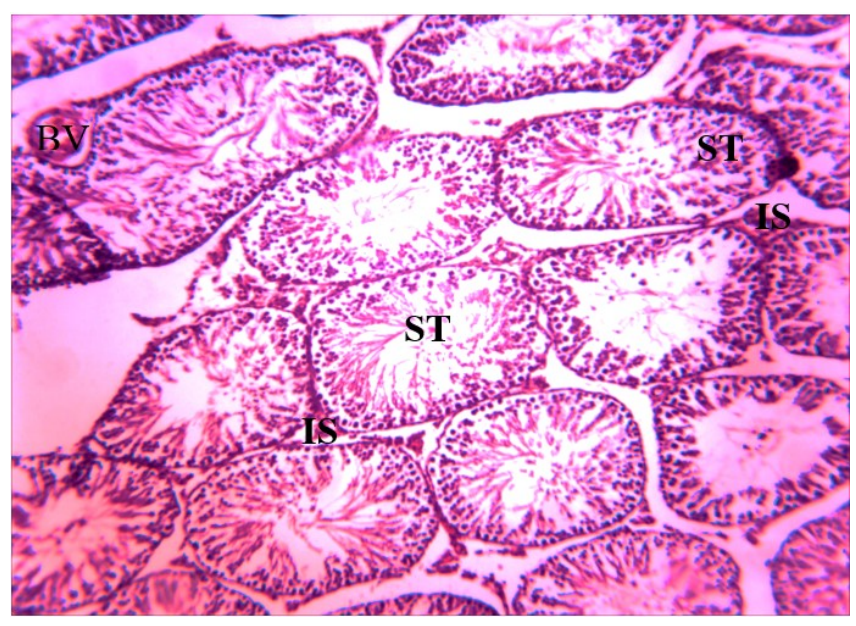

Plate 1 (Group I) showed normal histoarchitecture of the seminiferous tubules, normal view of interstitial spaces with abundant Leydig cells. The tunica albuginea was intact with normal cellular orientation and intact basement membrane. H\&E. x 100. Keys: IS-Interstitial space, ST - seminiferous tubule, BV - blood vessel

\section{Discussion}

Spermatogenesis is considered as a major target of defects in male infertility; about $70 \%$ of genes essential for male infertility have been demonstrated to be involved in this process [19]. The current study investigated the histomorphological effects of oral administration of low dose of cottonseed oil on the testes of Wistar rats in order to discern what analogous 


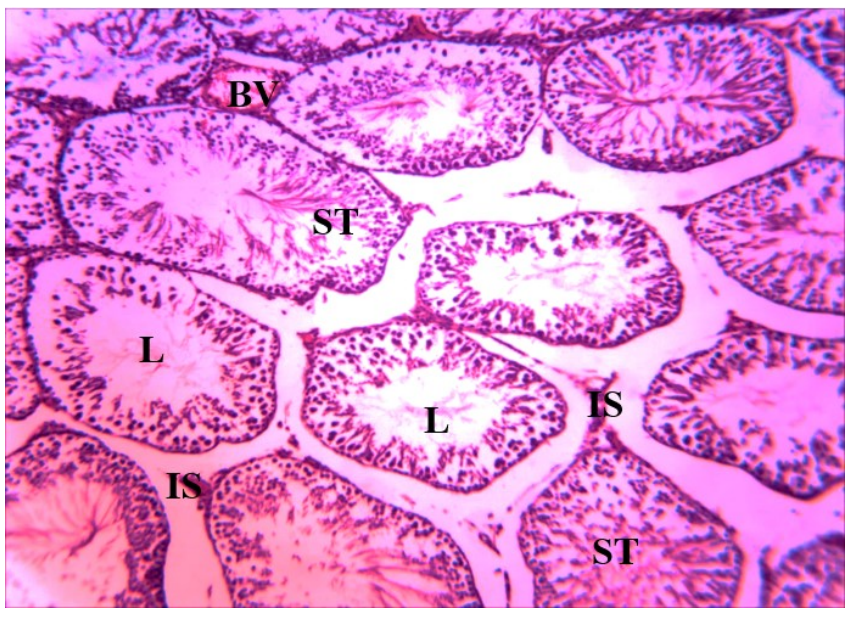

Plate 2 (Group II) showed the seminiferous tubules being attached to the wall of the testicular lobule. The seminiferous tubules were detached from each other giving room for noticeable interstitial spaces with few to many Leydig cells. The basement membrane was intact while there was an increase in the widening of the seminiferous tubule lumen as compared to the control group. H\&E. x 100. Keys: IS-Interstitial space, $\mathrm{ST}$ - seminiferous tubule, BV - blood vessel, L - lumen.

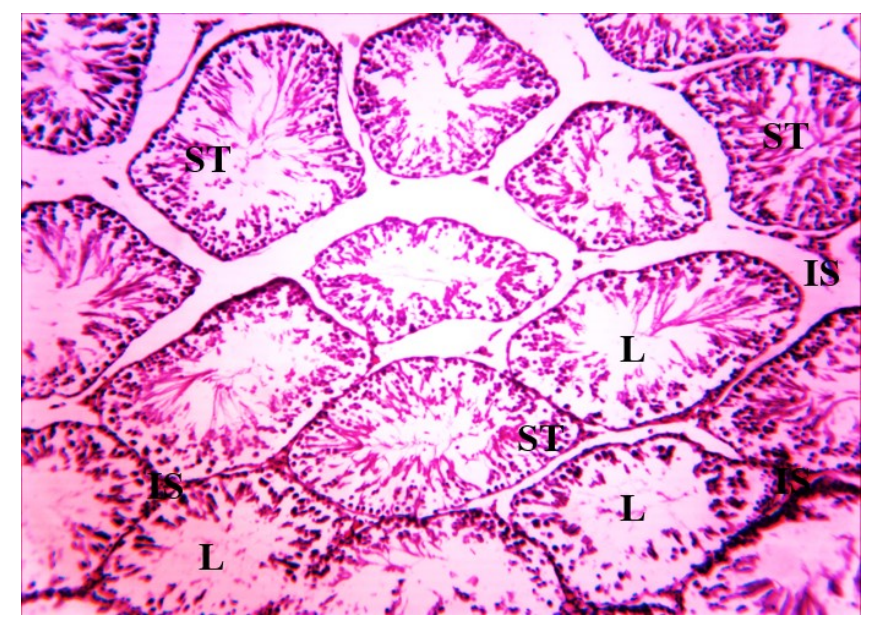

Plate 3 (Group III) showed the disorientation of the seminiferous tubules of the basal layer. Some seminiferous tubules at the centre were detached from each other giving rooms for a noticeable interstitial space with sparse Leydig cells. Some tubules appeared intact. H\&E. x 100. Keys: IS-Interstitial space, ST - seminiferous tubule, BV - blood vessel, L - lumen.

effect it might have in males using cottonseed oil products and those using it as an oral contraceptive. Findings from this study revealed the increase in the luminal surface of the seminiferous tubules, the decrease in the Leydig cell population, the disorientation of spermatogenic series and the detachment of spermatogenic cells from the basal layer and germinal epithelium.

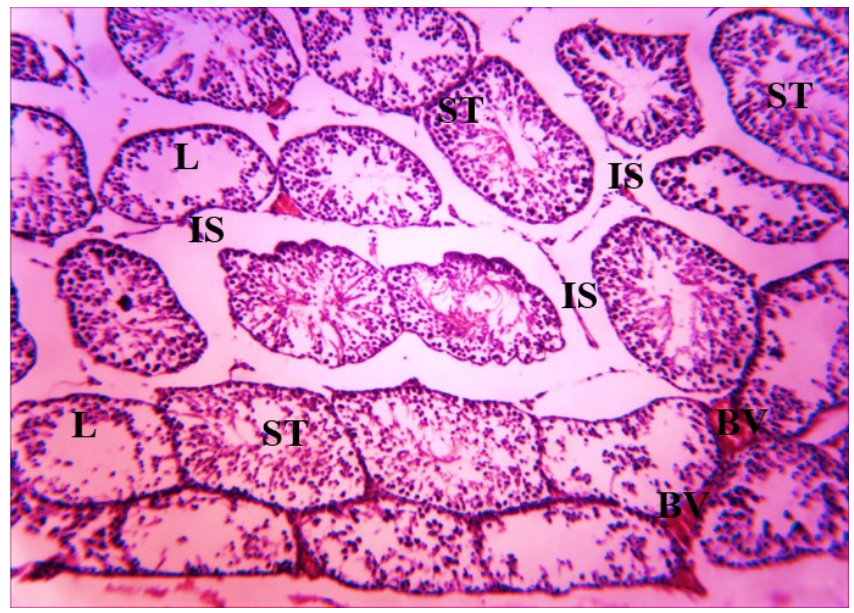

Plate 4 (Group IV) showed noticeable changes that were pronounced in the interstitial spaces containing very few Leydig cells with some spaces replaced by congested blood vessels. There was a disorientation in the spermatogenic series, detachment of spermatogonia from the basal layer with the distortion in the basal layer of the seminiferous tubule. H\&E. x 100. Keys: IS-Interstitial space, ST - seminiferous tubule, BV blood vessel, L - lumen.

The study demonstrated that male Wistar rats administered varying doses of cottonseed oil showed a dose-dependent increase in the lumen of the seminiferous tubules. This seminiferous tubule widening was a result of exfoliation of spermatogenic cells. This implied that gossypol transversed the tight blood testes barrier, altered spermatogenic cell arrangement which in turn led to an increase in the luminal diameter. The blood testis barrier was described as a physical barrier between the seminiferous tubules of the testes and blood vessels [20]. Kim (2010) reported that the barrier prevented the passage of cytotoxic agents into the seminiferous tubules and shielded the germ cells from blood-borne obnoxious agents [20].

Findings from the present study showed the degeneration of the Leydig cells and a dose-dependent decrease in the Leydig cell population. With an increase in dosage and duration of cottonseed oil action, the Leydig cells exhibited degenerative features which led to their reduction and replacement of the interstitial space with congested blood vessels. The Leydig cells have been reported as the primary source of the steroid hormone "testosterone" and they are located adjacent to the seminiferous tubules in the testes [21]. A reduction in the number of the Leydig cell implied a decrease in the production of testosterone either by gossypol action on the release of luteinizing hormone by the pituitary gland or by its direct action on the Leydig cells. This observation agreed with the study by Hardley et al. (1981), and Paim et al. (2015), who noted that the administration of gossypol led to a decrease in the Leydig cell number and a reduction in the production of testosterone $[14,16]$. 
Furthermore, the index study revealed a dose-dependent distortion of the spermatogenic series accompanied with the detachment of spermatogenic cells from the basal layer. This finding was evident in the group that received the highest dose. Spermatogenesis was described as a process by which haploid spermatogonia developed from germ cells in the seminiferous tubules of the testes [19]. This process was initiated with mitotic divisions of the spermatogonia type A which was located close to the basal layer. Developing germ cells were arranged in an orderly pattern in the epithelium of the seminiferous tubules so that they can be nurtured by the Sertoli cells throughout their development without disruption [22]. Consequently, this spermatid polarity was held together by spermatogenic adhesion protein complexes at the actin-rich apical ectoplasmic specialization ( $\alpha 6 \beta 1$ - integrin - laminin $-\alpha 3, \beta 3, \gamma 3$ and nectin -3 - afadin), for cell to cell junctions at the Sertoli cell-to-cell interface, they are supported by adhesion complexes at the actin-based basal ectoplasmic specialization (N-cadherin - B - catenin and nectin -2-afadin), tight junction (occluding $-20-1$ and claudin 11-20-1) and gap junctions (connexin 43-plakophilin-2) and intermediate filament-based desmosomes (desmoglein - 2-desmocollin- 2) $[19,22]$. Although, the exert mechanism of gossypol action on the spermatogenic series has not been reported, the resultant pattern indicated that gossypol altered the protein adhesion molecules in the seminiferous tubules which led to the disorientation. This observation agreed with findings from studies that reported that oral administration of gossypol caused the distortion of spermatogenesis $[3,6,7,8,23,24,25]$.

\section{Conclusions}

Oral administration of cottonseed oil in male Wistar rats caused the increase in the seminiferous tubule luminal diameter, the decrease in the Leydig cell population, the disorientation of spermatogenesis and the detachment of spermatogenic cells from the basal layer. This effect could be produced through direct effects of gossypol on blood testis barrier, the pituitary gland or spermatogenic adhesion molecules.

\section{Prospects for further research}

The study indicated a deleterious effect of cottonseed oil in the testes. Males who are willing to reproduce should stop the usage of gossypol oral contraceptive as a birth control pill. In addition, more studies should be conducted on the mechanism of gossypol action to establish the molecular basis for the observed findings.

\section{Conflicts of interest}

There is no potential conflict of interest with respect to the research ownership and/or publication of the article

\section{References}

[1] Kovacic P. Mechanism of drug and toxic actions of metabolic effects of the anti-fertility agent, gossypol, on various reproductive organs of male mice. Int J Androl. 2003;3:507-518.

[2] Wang X, Plhak LC. Production, characterization, and application of anti-gossypol polyclonal antibodies. J Agric Food Chem. 2000;48:5109-5116. DOI: https : / / doi . org/10.1021/jf0006022 [PMid:11087445]

[3] Chang MC, Gum ZP, Saksena SK. Effect of gossypol on the fertility of male rats, hamsters and rabbits. Contraception. 1980; 21:461-469. DOI: https : / / doi .org/ $10.1016 / 0010-7824(80) 90011-6$

[4] Shepu X, Shudong S, Yanwan W et al. Antispermatogenic effect of gossypol on the germinal epithelium of rat testes. Sci Sin. 1980;23:642. [PMid:7403840]

[5] Edwards JD. Total synthesis of gossypol. J Chem Soc. 1958;80:3798-3799. DOI: https://doi.org/10. 1021/ja01547a084

[6] Coutinho EM. Gossypol: a contraceptive for men. Contraception. 2002;65:259-263. DOI: https : / doi .org/ 10.1016/S0010-7824(02)00294-9

[7] Shandilya L, Clarkson TB, Adams MR, Lewis JC. Effects of gossypol on reproductive and endocrine functions of male cynomolgus monkeys (Macaca fascicularis). Biol Repro. 1982;27:241-252 DOI: https://doi.org/ 10.1095/biolreprod27.1.241

[8] Oko R, Hrudka F. Gossypol-induced early and delayedeffects in the seminiferous epithelium of the adult-rat. Contraceptive Del Syst. 1984;5:335-356.

[9] Liang SX, Pang SN, Dong RH, Dai RX. Radio Immunuoassay of Serum T and LH in male rat administered gossypol. Acta Biol Exp Sinica. 1981;14:91-97.

[10] Liu BS. A tentative ideal of the use of cooking cotton seed oil for fertility control. Shanghai J Chin Med. 1957;6:4347.

[11] Wright J, Bissonnette F, Duchesne C et al. Psychological distress and infertility: men and women respond differently in vitro. Fertil Steril. 1991;55:100-108. DOI: https://doi.org/10. 1016/S0015-0282(16)54067-9

[12] Coulson PB, Snell RL, Parise C. Short-term gossypol: focus on reactive oxygen species and electron transfer. Curr Med Chem. 1993;10(24):2711-2718.

[13] Messiha FS. Effect of gossypol on kinetics of mouse liver alcohol and aldehyde dehydrogenase. Gen Pharmacol. 1991;22(4):573-576. DOI: https ://doi .org/ $10.1016 / 0306-3623(91) 90058-E$ 
[14] Paim T, Viana $P$, Brandão $E$ et al. Impact of feeding cottonseed coproducts on reproductive system of male sheep during peripubertal period. Sci Agric. 2015;73(6):489-497 DOI: https://doi.org/10. 1590/0103-9016-2015-0377

[15] Kenfack A, Chombong JK, Ngoula F et al. Effect of feeding cottonseed cake on male fertility in rabbit. Bang J Anim. Sci. 2015;44(1):16-20. DOI: https : / / doi . org/10.3329/bjas.v44i1.23123

[16] Hardley MA, Young C, Lin, Dim M. Effects of gossypol on the reproductive system of male rats. J Androl. 1981;2:190-199. DOI: https://doi .org/10 . $1002 / j .1939-4640.1981$.tb00615.x

[17] Neena S, Meenakshi G. Effect of crude cottonseed oil containing gossypol on fertility of male and estrous cycle of female Bandicota bengalensis Gray and Hardwicke. J App Anim Res. 2013;41(2):156-165. DOI: https : / / doi.org/10.1080/09712119.2012.738230

[18] Burnett D, Crocker J. Specimen handling and preparation for routine diagnostic histopathology. In: The science of laboratory diagnosis. 2nd ed. John Wiley and sons, England. 2005;1:5-7.

[19] Linxi L, Ying G, Haiqi C et al. Cell polarity, cell adhesion and spermatogenesis; role of cytoskeletons. Facility Rev. 2017;61565. doi: [10.12688/f1000research.11421.1]

[20] Kim EB, Scott B, Sussan MB, Heddeven LB. Ganong's review of Medical Physiology. 24ed. TATA Mcgraw Hill. 2010;419-420.

[21] Al-Agha O, Axiotis C. An in-depth look at Leydig cell tumour of the testis. Arch Pathol Lab Med. 2007;131(2):311- 317.

[22] Sharma S, Hanukoglu A, Hanukoglu I. Localization of epithelial sodium channel $(\mathrm{ENaC})$ and $\mathrm{CFTR}$ in the germinal epithelium of the testis, Sertoli cells and spermatozoa. J Mol Histol. 2018;49(2):195-208. DOI: https : //doi.org/10.1007/s10735-018-9759-2

[23] Chenoweth PJ, Risco CA, Larsen RE et al. Effects of dietary gossypol on aspects of semen quality, sperm morphology and sperm production in young Brahman bulls. Theriogenology. 1994;42(1):1-13. DOI: https : / / doi . org/10.1016/0093-691X(94)90657-5

[24] Hassan ME, Smith GW, Ott RS et al. Reversibility of the reproductive toxicity of gossypol in peripubertal bulls. Theriogenology. 2004;61(6):1171-1179. DOI: https : / / doi.org/10.1016/j.theriogenology . 2003.07 .007 [PMid:15037004]

[25] El-Sharaky S, Newairy AA, Elguindy NM, Elwafa AA. Spermatotoxicity, biochemical changes and histological alteration induced by gossypol in testicular and hepatic tissues of male rats. Food Chem Toxicol. 2010;48(12):3354-3361. DOI: https://doi.org/ $10.1016 / j$. fct. 2010.09 .004

Received: 2018-10-25

Revised: $2018-11-25$

Accepted: 2018-11-25 